\title{
Article
}

\section{Intervening before the onset of Type 1 diabetes: baseline data from the European Nicotinamide Diabetes Intervention Trial (ENDIT)}

The European Nicotinamide Diabetes Intervention Trial (ENDIT) Group* • E. A. M. Gale (凶)

The European Nicotinamide Diabetes Intervention Trial (ENDIT) Group*

Diabetes and Metabolism, Division of Medicine, University of Bristol, Bristol, UK

E. A. M. Gale

Medical School Unit, Southmead Hospital, Bristol, BS10 5NB, UK

E. A. M. Gale

E-mail: edwin.gale@bristol.ac.uk

Received: 19 August 2002 / Revised: 13 November 2002 / Published online: 27 February 2003

\begin{abstract}
Aims/hypothesis To set up a clinical trial to establish whether nicotinamide can prevent or delay clinical onset of Type 1 diabetes.

Method The European Nicotinamide Diabetes Intervention Trial is a randomised, double-blind, placebo-controlled intervention trial undertaken in 18 European countries, Canada and the USA. Entry criteria were a first-degree family history of Type 1 diabetes, age 3-40 years, confirmed islet cell antibody (ICA) levels greater than or equal to 20 JDF units, and a non-diabetic OGTT; the study group was further characterised by intravenous glucose tolerance testing, measurement of antibodies to GAD, IA-2 and insulin and HLA class II genotyping.

Results ICA screening was carried out in approximately 30,000 first-degree relatives. A total of 1004 individuals fulfilled ICA criteria for eligibility, and 552 (288 male) were randomised to treatment. Of these, 331 were aged less than 20 years ( $87 \%$ siblings and $13 \%$ offspring of the proband with diabetes) and 221 were 20 years of age or more (76\% parents, $21 \%$ siblings and $3 \%$ offspring). Oral glucose tolerance was normal in 500 and impaired in 52 (9.4\%), and first phase
\end{abstract}


insulin response in the IVGTT was below the $10^{\text {th }}$ centile in $34 \%$. Additional islet autoantibodies were identified in 354 trial entrants. Diabetes-associated HLA class II haplotypes were found in $84 \%$ of the younger age group and $80 \%$ of the older group. The protective haplotype HLA-DQA $1 * 0102-D Q B 1 * 0602$ was found in $10 \%$ overall.

Conclusions/interpretation ENDIT has shown that a trial of an intervention designed to halt or delay progression to Type 1 diabetes can be carried out on a multinational collaborative basis, as and when potentially safe and effective forms of intervention become available. Primary screening with biochemically defined autoantibodies will substantially reduce the number of lower risk individuals to be included in future intervention trials

Keywords Type 1 diabetes $\cdot$ ENDIT $\cdot$ nicotinamide $\cdot$ prediction $\cdot$ prevention $\cdot$ ICA $\cdot$ DPT-1

\section{Abbreviations}

ENDIT European Nicotinamide Diabetes Intervention Trial

ICA Islet cell autoantibodies

IA-2 Protein tyrosine phosphatase IA-2

IAA Islet autoantibodies

FPIR First phase insulin response

IDS Immunology of Diabetes Society

SSO Sequence specific oligonucleotides

NOD Non-obese diabetic

$B B$ Bio-breed

PARP Poly (ADP)-ribose polymerase

$J D F$ Juvenile Diabetes Federation

* For a full list of the group members see acknowledgements

An erratum to this article can be found at http://dx.doi.org/10.1007/s00125-003-1202-9

Europe includes countries with the highest incidence of Type 1 (insulin-dependent) diabetes mellitus in the world. These rates continue to rise rapidly, and the EURODIAB TIGER Concerted Action has shown an annual 3 to $4 \%$ increase in the incidence of childhood diabetes across our continent [1]. In Finland, it is estimated that childhood diabetes is now four times as common as 
it was in the 1950s [2]. There is currently no means of preventing or curing this disorder. Type 1 diabetes can, however, be predicted by screening for islet autoantibodies, and both animal and human pilot studies suggest that prevention is possible. The US Diabetes Prevention Trial-Type 1 (DPT-1) has recently reported experience with parenteral insulin therapy in high risk relatives of an individual with Type 1 diabetes [3]. Here we show baseline data from a trial of high-dose oral nicotinamide, and demonstrate that a candidate preventive measure can be tested successfully on a multinational collaborative basis.

\section{Methods}

Study Design ENDIT is a randomised, double-blind, placebo controlled trial designed to test whether daily oral administration of high dose nicotinamide can produce a clinically useful reduction in the rate of progression to Type 1 diabetes in relatives at increased risk of contracting the disease. The null hypothesis is that nicotinamide at a dose of $1.2 \mathrm{~g} / \mathrm{m}^{2}$ cannot achieve a 35 to $40 \%$ reduction in the rate of progression to Type 1 diabetes over a five year period. The study is designed to have $90 \%$ power to detect such a difference at the $5 \%$ significance level, based on the assumption that non-diabetic first-degree relatives under the age of 40 with confirmed levels of islet cell antibodies (ICA) greater than or equal to $20 \mathrm{JDF}$ units have more than $40 \%$ risk of insulin therapy within 5 years. Sample size calculations showed that a minimum of 211 in each group would be needed to achieve this.

Inclusion Criteria First-degree relatives of patients who developed Type 1 diabetes before age 20, and who were themselves aged between 3 and 40 years, were eligible for screening. At the start of the study, the upper age limit for inclusion was 60 years, but this was lowered in 1995 following a multicentre analysis which showed that the risk associated with ICA in relatives above age 40 was low [4]. Family members over age 40 who had already been recruited and screened received an explanation of this revised risk estimate but were allowed to proceed to randomisation if they so wished.

Study organisation Study co-ordination and data management were carried out centrally. Participants have been identified via 354 local centres in 20 countries in Europe, Canada and the USA (Table 1). Participation in each country is organised through one to two national co-ordinators, who are responsible for all communications with local centres and for ensuring local compliance with the protocol. The protocol was approved by the research ethics committee or equivalent in 
each participating centre, and also by the appropriate national drug regulatory authorities. Written informed consent was obtained from all participants.

\section{[Table 1. will appear here. See end of document.]}

Screening Eligible first-degree relatives were screened for ICA. A second sample was requested from any relative with ICA greater than or equal to 5 JDF units on initial testing. Those with ICA greater than or equal to $20 \mathrm{JDF}$ units in at least one sample as measured in the central laboratory and with ICA greater than or equal to $5 \mathrm{JDF}$ units in the other sample were invited to undergo further evaluation.

Other inclusion criteria Prior to randomisation a full clinical assessment was carried out with determination of standard biochemical and haematological safety parameters, oral glucose tolerance test and intravenous glucose tolerance test. Height and weight were measured at the outset in all participants, and Tanner staging carried out on children; an X-ray of the left wrist was taken to estimate bone age in all children under the age of 14 .

Exclusion criteria Individuals with any chronic disease likely to affect outcome, toxicity or compliance, women who were breast feeding, pregnant or of child bearing age and not using effective contraception, and anyone taking vitamin preparations containing nicotinamide were excluded from the study. Those found to have diabetes on oral glucose tolerance testing were also excluded.

Oral glucose tolerance test (OGTT) Oral glucose ( $1.75 \mathrm{~g} / \mathrm{kg}$ body weight, up to a maximum of $75 \mathrm{~g}$ ) was administered following an overnight fast. Venous plasma samples collected at 0 and 120 minutes were tested for glucose in the local study centre laboratory, and diabetes and impaired glucose tolerance were defined using WHO criteria [5].

Intravenous glucose tolerance test (IVGTT) IVGTTs were carried out according to the ICARUS protocol [6]. A glucose dose of $0.5 \mathrm{~g} / \mathrm{kg}$, up to a maximum of $35 \mathrm{~g}$, was infused over $3 \min \pm 15 \mathrm{~s}$, and blood samples collected at $-5,0,1,3,5$ and $10 \mathrm{~min}$. First phase insulin response was calculated as the sum of the insulin levels at +1 and +3 min.

Islet cell antibodies The initial ICA assay in all or most samples was carried out in local laboratories in ten countries (Table 1), and all ICA testing was done in the central laboratory for the remainder. Samples found to have ICA greater than or equal to 5 JDF units in local laboratories were sent to the central laboratory for confirmation. All local laboratories participated in a sample exchange and workshop programme to ensure that assay sensitivity was maintained throughout the period of screening, but study entry was based solely upon results from the central laboratory. 
ICA determination in the central laboratory was performed by indirect immunofluorescence [7]. Briefly, sera were incubated on sections of human pancreas for $30 \mathrm{~min}$ at room temperature. After washing, bound antibody was revealed using a sheep anti-human immunoglobulin (GAM) FITC conjugate (TBS, Birmingham, UK). The sections were examined in a blinded fashion under a fluorescence microscope (Leica, Wetzlar, Germany) by two observers. All samples were initially assayed at a 1 in 2 dilution and assigned an arbitrary intensity score from 0 to 7 . Samples with an intensity score of 1 or greater were re-assayed in a quantification assay [8], while those samples with an intensity score of less than 1 were considered negative. Five standards and two internal controls were included in each assay. Overall assay performance was monitored by the inclusion of 3 coded "external" quality control samples in every 100 samples assayed and the inter assay co-efficient of variation (CV) of the ICA assay was $51 \%$ at $14 \mathrm{JDF}$ units, $35 \%$ at $38 \mathrm{JDF}$ units and $22 \%$ at 60 JDF units. The ICA assay achieved $81 \%$ sensitivity with $86 \%$ specificity in the First Immunology of Diabetes Society (IDS) Combined Antibody Workshop [9]. A number of pancreas substrates were used during the course of the study. To maintain consistency, each new substrate was evaluated in parallel with the old substrate by measuring ICA on a panel of 140 samples. GAD and IA-2 ${ }_{i c}$ autoantibodies Autoantibodies to GAD and IA- $2_{\text {ic }}$ were measured in radiobinding assays in the Division of Medicine, University of Bristol, UK [10], and considered positive if above the $97.5^{\text {th }}$ centile of a control population of 2860 schoolchildren. The GAD antibody assay achieved $91 \%$ sensitivity with $99 \%$ specificity, and the IA-2 antibody assay achieved $74 \%$ sensitivity with $99 \%$ specificity in the first Immunology of Diabetes Society (IDS) combined antibody workshop [9].

Insulin autoantibodies Samples were assayed for insulin autoantibodies in the Division of Medicine, University of Bristol, UK [11], using a format similar to that used for measuring GAD and IA-2 antibodies. Immune complexes were isolated using protein A sepharose. Bound counts for each sample were calculated after subtraction of background counts, and results were expressed in arbitrary units derived from a standard curve. Sera with insulin binding above 0.4 units were tested in a competition assay in which each sample was incubated with label in the presence of excess unlabelled insulin (Humulin, Lilly, Basingstoke, Hants, UK). Specific bound counts were converted into arbitrary units as described above. Samples assayed for insulin autoantibodies were considered positive if they had levels above the $97.5^{\text {th }}$ centile of the schoolchildren. The assay achieved $58 \%$ sensitivity with $99 \%$ specificity on the samples included in the First IDS Combined Antibody Workshop [9]. 
Insulin assay Plasma insulin was measured in a single laboratory at the Steno Diabetes Centre, Gentofte, Denmark using an enzyme-linked two-site immunoassay [12]. The method uses two murine monoclonal antibodies that bind to different epitopes on the insulin molecule and shows a less than $1 \%$ cross-reactivity with intact human proinsulin. During the course of the study, kits produced by two manufacturers (ELISA, Dako, Ely, UK) and (Autodelfia, Wallac Oy, Turku, Finland) were used for insulin measurement. The kits were based on the same immunochemistry and detailed method comparison showed results obtained by both methods to be essentially identical. To allow comparison of IVGTT results with FPIR centiles obtained in the University of Washington, Seattle and used for DPT-1, 105 samples spanning the range $0-500 \mathrm{pmol} / 1$ were assayed in both laboratories. The regression equation of insulin concentration measured in Seattle on the insulin concentration measured in the Steno laboratory was used to derive a correction factor to standardise the measurement to the Seattle assay [13].

HLA genotyping HLA genotyping was carried out in the Institute of Transplantation Immunology, National Hospital, Oslo, Norway. Typing of HLA-DQA1, -DQB1 and -DRB1*04 subtypes were mainly done using PCR-SSO [14]. A few samples were also typed for DQA1, DQB1 and/or DRB1*04 subtypes with an allele specific PCR kit (Olerup SSP Genovision, Oslo, Norway) and/or with a reverse dot-blot kit (Reli-SSOP, Dynal, Oslo, Norway).

\section{Results}

First-degree relatives were screened from 20 countries (Table 1). Initial ICA testing on approximately 16000 samples was carried out in local laboratories and 3402 of these were sent to the central laboratory for confirmation of ICA positivity, while samples from a further 13718 relatives were first tested for ICA in the central laboratory. Approximately $16 \%$ of those tested were above age 40 when the first screening sample was collected.

A total of 1004 individuals fulfilled the ICA criteria for eligibility of whom 552 were randomised. The reasons for non-randomisation of the remainder are shown in Fig. 1.

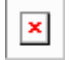

Fig. 1. Subject disposal

Nationality is shown in Table 1 and other subject characteristics are shown in Table 2. Of 552 relatives randomised, 331 were below age 20 years and 221 aged more than 20 . In the younger 
age group $87 \%$ were siblings of a diabetic proband and $13 \%$ were offspring. In the older age group $21 \%$ were siblings, $76 \%$ were parents and $3 \%$ were offspring.

[Table 2. will appear here. See end of document.]

Islet autoantibodies Overall, $64 \%$ of those randomised had at least one other antibody marker in addition to ICA, representing $76 \%$ of those aged less than 20 and $46 \%$ of those above this age. HLA class II The diabetes-associated haplotypes HLA-DQA1*03-DQB1*0302 (DQ8) and/or HLA-DQA $1 * 0501-D Q B 1 * 0201$ (DQ2) were found in $84 \%$ of the younger age group and $80 \%$ of the older group. The high-risk DQ2/DQ8 heterozygous genotype was found in $23 \%$ of the younger and $14 \%$ of the older group respectively. The protective HLA-DQA1*0102-DQB1*0602 (DQ6) was found in $8 \%$ of those below age 20 and $12 \%$ of the older group. This haplotype was associated with ICA alone in 26 individuals, with one additional antibody in 11, with two additional antibodies in four, and with three additional antibodies in nine individuals. For technical reasons, genotyping could not be carried out on 33 samples (21 below age 20).

Oral glucose tolerance Overall, of 552 individuals randomised, 52 (9\%) had impaired glucose tolerance (IGT) by WHO criteria in the initial oral glucose tolerance test. Those with ICA alone were less likely to have IGT than those with additional antibodies ( $4 \%$ vs. $\left.12 \%, \chi^{2}=10.5, p=0.001\right)$. Of 50 individuals with DQ6, $10 \%$ had IGT compared with $9 \%$ in the remainder. $\left(\chi^{2}=0.04, p=0.85\right)$. First phase insulin response The median (range) first phase insulin response, measured as $1+3 \mathrm{~min}$ insulin levels in the intravenous glucose tolerance test, was $362 \mathrm{pmol} / 1$ (43-1960 pmol/l) in those under age 20 years and $476 \mathrm{pmol} / 1$ (8-2666 pmol/1) in the older age group. Overall, 164 of 487 tested (34\%) had FPIR below the equivalent of the $10^{\text {th }}$ centile used as an entry criterion for the parenteral arm of DPT-1; 100 individuals in the younger age group (34\%) and 64 in the older age group (33\%). Those with ICA alone were less likely to have an FPIR below the $10^{\text {th }}$ centile than those with additional antibodies ( $19 \%$ vs. $\left.42 \%, \chi^{2}=26.52, p<0.0001\right)$. The frequency of low FPIR was however similar in individuals with an HLA-DQ6 haplotype and those who did not carry the protective haplotype $\left(27 \%\right.$ vs. $\left.34 \%, \chi^{2}=1.11, p=0.29\right)$. For technical reasons, including sample haemolysis, FPIR was not available on 65 individuals (38 below age 20).

\section{Discussion}

The prodromal phase preceding the onset of Type 1 diabetes is characterised by progressive beta-cell destruction and the appearance of circulating islet autoantibody markers, thus providing an opportunity for intervention to halt or delay the disease process. Prophylaxis of diabetes has 
been achieved, sometimes with lasting protection, using a variety of interventions in two animal models of spontaneous autoimmune diabetes, the NOD mouse and the BB rat. Early human studies of immune intervention concentrated on the attempt to prolong beta-cell function in recently diagnosed patients requiring insulin therapy. Prospective randomised placebo controlled double-blind studies showed, for example, that Cyclosporin A can protect beta-cell function to the extent that some $25 \%$ of patients on Cyclosporin were able to control their diabetes on diet alone one year after diagnosis, as against 5 to $10 \%$ of controls $[15,16]$. Unfortunately this benefit does not persist, and the high rate of complications has limited this approach to therapy. Since the great majority of beta-cells seem to have been destroyed by the time of clinical presentation, it seems reasonable to conclude that earlier intervention, at a stage when the beta-cell mass is relatively intact, could produce a more lasting benefit.

Once autoimmunity has been activated, beta cells are destroyed by a cellular immune response which involves cytotoxic $\mathrm{T}$ cells and macrophages and results in release of proinflammatory cytokines. Impaired insulin secretion and beta-cell damage are thought to result from generation of nitric oxide and/or oxygen free radicals within the cell [17]. Single strand DNA damage leads to activation of the DNA repair enzyme poly(ADP-ribose) polymerase (PARP). PARP is an abundant nuclear protein which shuttles onto and repairs DNA strand breaks. In doing so it consumes nicotinamide adenine dinucleotide (NAD), transferring the dinucleotide moiety of NAD to poly (ADP-ribose). Activation of PARP thus results in depletion of intracellular NAD levels, resulting in a rapid fall in available intracellular energy levels. Excessive activation of PARP and depletion of intracellular NAD levels are precursors of cell death. Excessive poly (ADP-ribose) formation due to PARP activation contributes to programmed cell death through energy starvation as the result of NAD consumption. The protective effect of nicotinamide upon murine beta cells is thought to be mediated by this pathway $[18,19,20,21]$, but it could differ in its effects upon human beta cells [22]. Previous trials in high risk individuals have reached conflicting conclusions $[23,24]$.

Nicotinamide is the amide of nicotinic acid; both are components of vitamin B3. Although their action as anti-pellagra vitamins is similar, their metabolic effects are quite different. In particular, nicotinic acid has clinical uses as a vasodilator and lipid lowering agent, and induces insulin resistance. These effects are not seen to any significant extent with nicotinamide, and insulin secretion is unaffected [25] although it has also been reported to induce a milder degree of insulin resistance [26]. Nicotinamide is water-soluble, and readily absorbed by mouth. Pharmacokinetic studies carried out by our group have shown that human metabolism is predominantly by 
methylation to N-methyl-2-pyridone-5-carboxamide, in which form it is excreted in the urine; oxidation to nicotinamide oxide also occurs, but there is no direct conversion to nicotinic acid [27,28]. At high doses, such as those used in ENDIT, peak levels of nicotinamide of $0.3-1.0 \mathrm{mmol} / \mathrm{l}$ are seen in the circulation; the $50 \%$ inhibition concentration of nicotinamide for PARP is about $0.1 \mathrm{mmol} / 1$ [29]. The safety profile of high dose nicotinamide has been reviewed, and the ratio of risk to benefit would be highly favourable if efficacy can be shown [30].

First-degree relatives of a child with Type 1 diabetes are at increased risk of progression to the disease, and are highly motivated to participate in such studies; it is therefore logical to offer intervention to people in this category. Although now largely superseded by measurement of other autoantibodies, ICA for many years formed the basis of diabetes prediction, and were used to identify high risk of progression in ENDIT, as in current US studies of intervention in pre-type 1 diabetes [3]. Family studies have shown that 2 to $2.5 \%$ of siblings and parents of a child with diabetes have ICA greater than or equal to $20 \mathrm{JDF}$ units, and that $40 \%$ of those aged less than 40 years will progress to insulin treatment within 5 years of first detection. This risk is increased if additional autoantibodies to GAD, IA-2 or insulin are detected [31,32], or if first phase insulin secretion is impaired [4].

The US Diabetes Prevention Trial-Type 1 (DPT-1) started shortly after ENDIT and has screened more than 70000 first-degree relatives for ICA. The results of intervention using parental insulin have recently been reported [3], and a second trial using oral insulin is in progress. These studies require very large-scale participation, and in Europe are most logically done on a multinational basis. For this reason simple robust entry criteria were selected for ENDIT, and the IVGTT was not used as a randomisation criterion. The parenteral arm of DPT-1 required an FPIR below $10 \%$ of a control population, and $37 \%$ of ENDIT participants would have fallen into this category. Since DPT-1 selected individuals with a low insulin response, it is not surprising that $33 \%$ had evidence of metabolic decompensation in the form of impaired glucose tolerance, as against $9 \%$ of those in ENDIT.

When ENDIT was planned (the study began in 1994), risk assessment by means of autoantibodies other than ICA had not been validated. Since then it has been shown that primary screening for autoantibodies against biochemically defined islet antigens has the potential to provide an enriched sample for future intervention trials [33]. In the light of present knowledge we would now have excluded the 198 ENDIT participants who had ICA without other islet autoantibodies, and we have confirmed a lower rate of IGT and low FPIR in this group. Other intervention studies have also excluded patients carrying the protective haplotype HLA-DQA1*0102-DQB1*0602 (DQ6) 
[3]. Within ENDIT, however, of 50 individuals with DQ6, 26 had ICA alone but the remainder had more than one autoantibody; nine had all four. In addition the frequency of both low FPIR and IGT in the subgroup with DQ6 were similar to those in the individuals who did not carry this haplotype. Further study will be needed to establish which individuals with DQ6 should be excluded from future intervention trials.

The outcome of ENDIT will be announced shortly, but we have learned several lessons. First, and most important, we have established that it is feasible to launch a multinational collaborative intervention trial involving both Europe and North America. In consequence, promising interventions can now be tested before the onset of end-stage beta-cell failure. The corollary is, however, that intervention at this stage of the disease must be undertaken on a continental scale, which means that only the most promising interventions can be tested in this way. Validated surrogate end-points for diabetes development would shorten the time scale of such interventions, but have yet to be developed. For this reason the current emphasis is upon testing interventions which might offer beta-cell rescue following clinical diagnosis of Type 1 diabetes, although this carries the risk that interventions of possible value earlier in the disease pathway might be discarded because they are ineffective in the latter stages of the disease [34]. As and when future interventions become available however, ENDIT has shown that high quality, relatively low-budget interventions before clinical onset can be carried out on a multinational collaborative basis, as and when potentially safe and effective forms of intervention become available. It is to be hoped that Europe will be able to develop funding mechanisms capable of supporting such long-term ventures.

Acknowledgements The final phase of ENDIT was funded by Juvenile Diabetes Research Foundation grant 4-2000-943; earlier phases were funded by European Union grants PL92 0957 and PL95 0771. We are grateful to Novo Nordisk for additional financial support throughout the period of the trial and for their help in provision of the trial tablets. We thank the many technical, nursing and medical staff in the participating centres for all their help in running the trial.

*The ENDIT Group:

Co-ordinator: E.A.M. Gale; Deputy Co-ordinators: P.J. Bingley, M. Knip.

Study Administrators: C.L. Emmett, H. Swankie, S. Fewell, P. Kearsey.

National Co-ordinators: Austria: E. Schober; Belgium: F.K. Gorus; Canada: J. Dupre, J. Mahon; Croatia: V. Profozic; Denmark: J.I. Reimers; T. Mandrup-Poulsen; England: P.J. Bingley; Finland: M. Knip; France: C. Levy-Marchal; Germany: C. Jaeger; Greece: C. Bartsocas, A. Vazeou; Hungary: M. Györko, G. Soltesz, L. Madacsy, Italy: M.R. Pastore, P. Pozzilli; Northern Ireland: 
D.J. Carson, H. Tennett; Norway: K. Dahl-Jørgensen, G. Joner; Poland: I. Kinalska, A.

Mrozikiewicz; Russia: Y. Vaykhonsky; Scotland: K. Robertson; Spain: A. de Leiva, M.T.

Martinez-Larrad, M. Serrano-Rios; Sweden: J. Ludvigsson; Switzerland: E.J. Schoenle; Texas:

W.J. Riley; Turkey: M.T. Yilmaz.

Laboratory Support: University of Bristol:, K.M. Gillespie, H. Gillmor, W.P.T. Moore, A.

Norcross, A.J.K. Williams; Steno Diabetes Centre, Gentofte: B. Dinesen, S. Kjellberg, T.

Mandrup-Poulsen, H. Niebling; National Hospital, Oslo: H.E. Akselsen, E. Thorsby, D.E. Undlien.

Data and Safety Monitoring Committee: A.L. Drash, O. Aagenes, G. Dahlquist, A. Laupacis,

A.E.M. McLean, J. Nerup, B. Weber.

Writing Committee: E.A.M. Gale, P.J. Bingley, C.L. Emmett.

\section{References}

1. EURODIAB ACE Study Group (2000) Variation and trends in incidence of childhood diabetes in Europe. Lancet 355:873-876

2. Tuomilehto J, Karvonen E, Pitkaniemi J et al. (1999) Record-high incidence of type 1 (insulin-dependent) diabetes in Finnish children. The Finnish Childhood Type 1 Diabetes Registry Group. Diabetologia 42:655-660

3. Diabetes Prevention Trial-Type 1 Diabetes Study Group (2002) Effects of insulin in relatives of patients with type 1 diabetes mellitus. New Engl J Med 346:1685-1691

4. Bingley PJ for the ICARUS Group (1996) Interactions of age, islet cell antibodies, insulin autoantibodies and first phase insulin response in predicting risk of progression to IDDM in relatives: the ICARUS data set. Diabetes 45: 1720-1728

5. World Health Organization (1985) Diabetes mellitus: Report of a WHO Study Group. WHO Technical Report Series No 727, World Health Organisation, Geneva

6. Bingley PJ, Coleman P, Eisenbarth GS et al. (1992) Standardization of NGTT to predict IDDM. Diabetes Care 15:1313-1316

7. Williams AJK, Bingley PJ, Moore WPM, Gale EAM and the ENDIT screening group (2002) Islet autoantibodies, nationality and gender: a multinational screening study in first-degree relatives of patients with Type I diabetes. Diabetologia 45:217-223

8. Bonifacio E, Bingley PJ, Shattock M et al. (1990) Quantification of islet cell antibodies and prediction of insulin-dependent diabetes. Lancet 335:147-149

9. Verge CF, Stenger D, Bonifacio E et al. (1998) Combined use of autoantibodies (IA-2 autoantibody, GAD autoantibody, insulin autoantibody, cytoplasmic islet cell antibodies) in type 1 diabetes: Combinatorial Islet Autoantibody Workshop. Diabetes 47:1857-1866

10. Bingley PJ, Bonifacio E, Williams AJK, Genovese S, Bottazzo GF, Gale EAM (1997) Prediction of IDDM in the general population: strategies based on combinations of autoantibody markers. Diabetes 46:1701-1710

11. Williams AJK, Bingley PJ, Bonifacio E, Palmer JP, Gale EAM (1997) A novel microassay for insulin autoantibodies. J Autoimmun 10:473-478

12. Andersen L, Dinesen B, Jørgensen PN, Poulsen F, Røder ME (1993) Enzyme immunoassay for intact human insulin in serum or plasma. Clin Chem 39:578-582

13. McCulloch DK, Bingley PJ, Colman R, Jackson R, Gale EAM, ICARUS group (1993) Comparison of bolus and infusion protocols for determining acute insulin response to intravenous glucose in normal humans. Diabetes Care 16:911-915 
14. Undlien DE, Friede T, Rammensee HG et al (1997) HLA-encoded genetic predisposition in IDDM: DR4 subtypes may be associated with different degrees of protection. Diabetes 46:143-149

15. Feutren G, Papoz L, Assan R et al. (1986) Cyclosporin increases the rate and length of remission in insulin-dependent diabetes of recent onset. Results of a multicentre double-blind trial. Lancet ii: 119-124

16. Canadian-European Randomized Control Trial Group (1988) Cyclosporin-induced remission of IDDM after early intervention: association of lyr of Cyclosporin treatment with enhanced insulin secretion. Diabetes 37:1574-1582

17. Eizirik DL, Pavlovic D (1997) Is there a role for nitric oxide in beta cell dysfunction and damage in IDDM? Diabet Metab Rev 13:293-307

18. Zhang J, Dawson VL, Dawson TM, Snyder SH (1994) Nitric oxide activation of poly (ADP-ribose) synthetase in neurotoxicity. Science 263:687-689

19. Mandrup-Poulsen T, Reimers JI, Andersen HU et al. (1993) Nicotinamide treatment in the prevention of insulin-dependent diabetes mellitus. Diabetes Metab Rev 9:295-309

20. Burkart V, Wang Z-Q, Radons J et al. (1999) Mice lacking the poly (ADP-ribose) polymerase gene are resistant to pancreatic beta cell destruction and diabetes development induced by Streptozocin. Nat Med 5:314-319

21. Kolb H, Burkart V (1999) Nicotinamide in type 1 diabetes. Mechanism of action revisited. Diabetes Care 22 [Suppl 2]: B16-B20

22. Hoorens A, Pipeleers D (1999) Nicotinamide protects human beta cells against chemically-induced necrosis, but not against cytokine-induced apoptosis. Diabetologia 42:55-59

23. Elliott RB, Chase HP (1991) Prevention or delay of Type 1 (insulin-dependent) diabetes mellitus in children using nicotinamide. Diabetologia 34:362-365

24. Lampeter EF, Klinghammer A, Scherbaum WA et al. (1998) The Deutsche Nicotinamide Intervention Study: an attempt to prevent Type 1 diabetes. Diabetes 47:980-984

25. Bingley PJ, Caldas C, Bonfanti R, Gale EAM (1993) Nicotinamide and insulin secretion in normal subjects. Diabetologia 36:675-677

26. Greenbaum CJ, Sears KL, Kahn SE, Palmer JP (1996) Nicotinamide's effect on glucose metabolism in subjects at risk for IDDM. Diabetes 45:1631-1634

27. Gillmor HA, Bolton $\mathrm{CH}$, Hopton $\mathrm{H}$ et al. (1999) Measurement of nicotinamide and $\mathrm{N}$-methyl-2-pyridone-5-carboxamide in plasma by high performance liquid chromatography. Biomedical Chromatography 13:360-362

28. Moore WPT, Bolton CH, Downs, L, Gillmor HA, Gale EAM (2000) Measurement of n-methyl-2-pyridone-carboxamide in urine by high performance liquid chromatography. Biomed Chromatogr 14:69-71

29. Pociot F, Reimers JI, Andersen HU (1993) Nicotinamide-biological actions and therapeutic potential in diabetes prevention. IDIG Workshop, Copenhagen, Denmark, 4-5 December 1992. Diabetologia 36:574-576

30. Knip M, Douek IF, Moore WPT et al. (2001) Safety of high-dose nicotinamide: a review. Diabetologia 43:1337-1345

31. Bingley PJ, Christie MR, Bonifacio E et al. (1994) Combined analysis of autoantibodies improves prediction of IDDM in islet cell antibody-positive relatives. Diabetes 43:1304-1310

32. Verge CF, Gianini R, Kawaski E et al. (1996) Prediction of type 1 diabetes in first-degree relatives using a combination of insulin, GAD and ICA512bdc/IA-2 autoantibodies. Diabetes 45:926-933

33. Bingley PJ, Williams AJK, Gale EAM (1999) Optimized autoantibody-based risk assessment in family members: implications for future intervention trials. Diabetes Care 22:1796-1801

34. Kolb H, Gale EAM (2001) Does partial preservation of residual $\beta$-cell function justify immune intervention in recent onset Type I diabetes? Diabetologia 44:1349-1353 

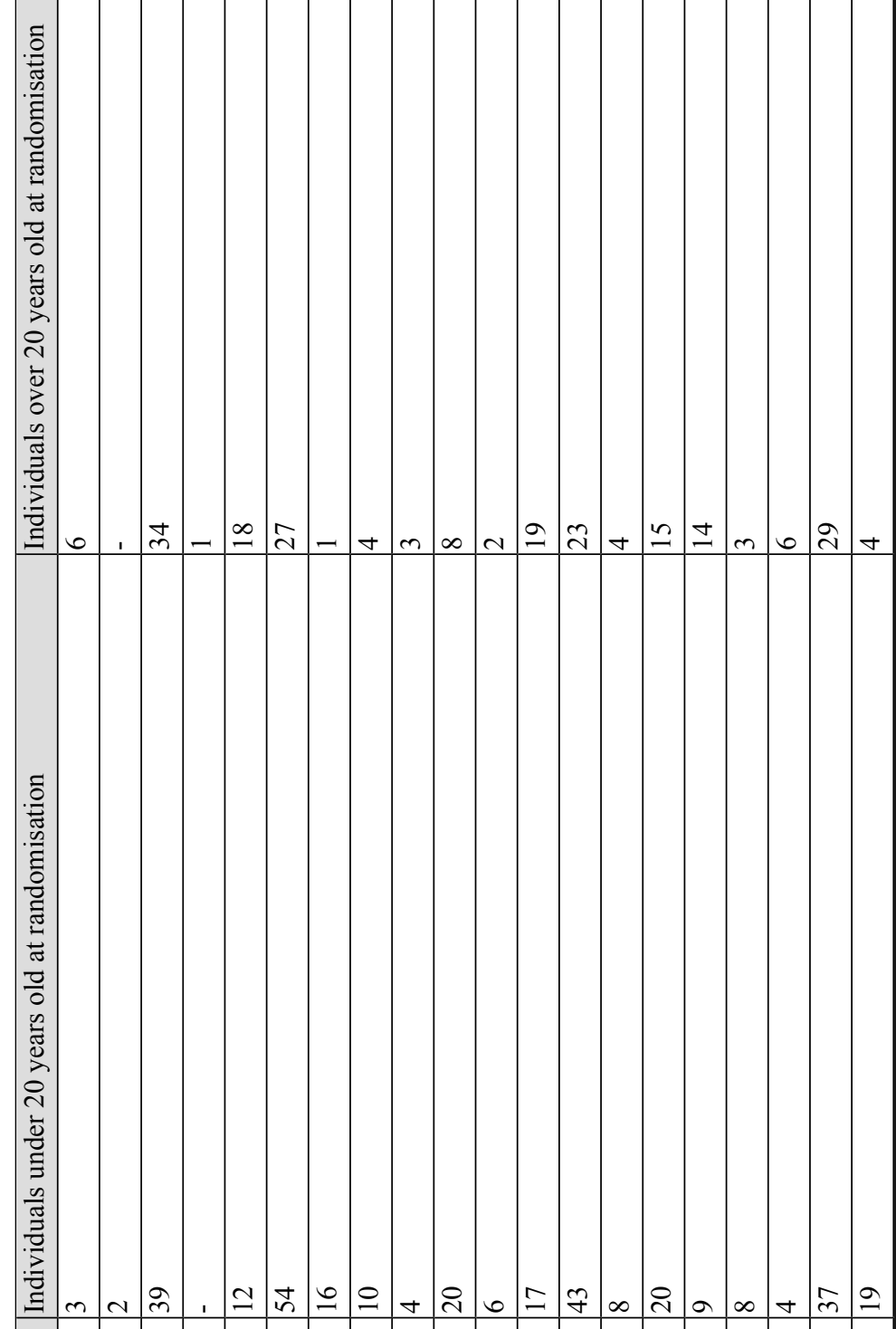

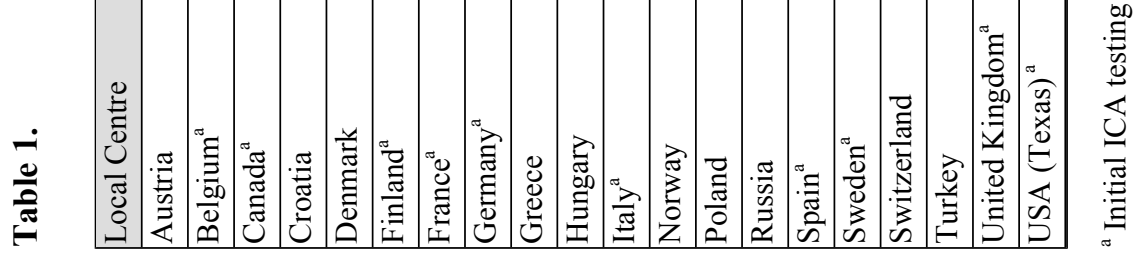




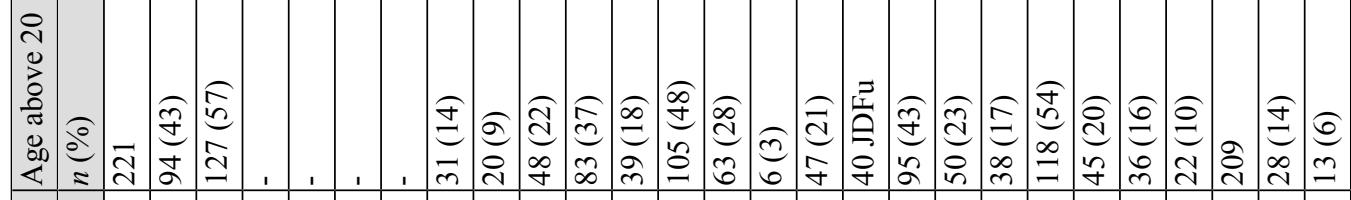

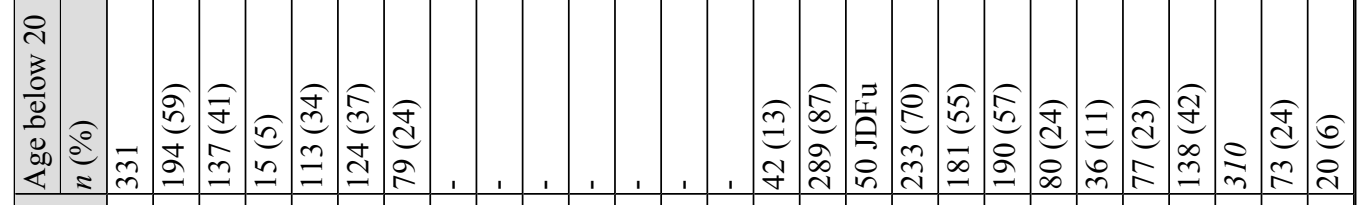

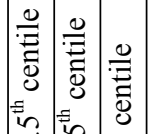

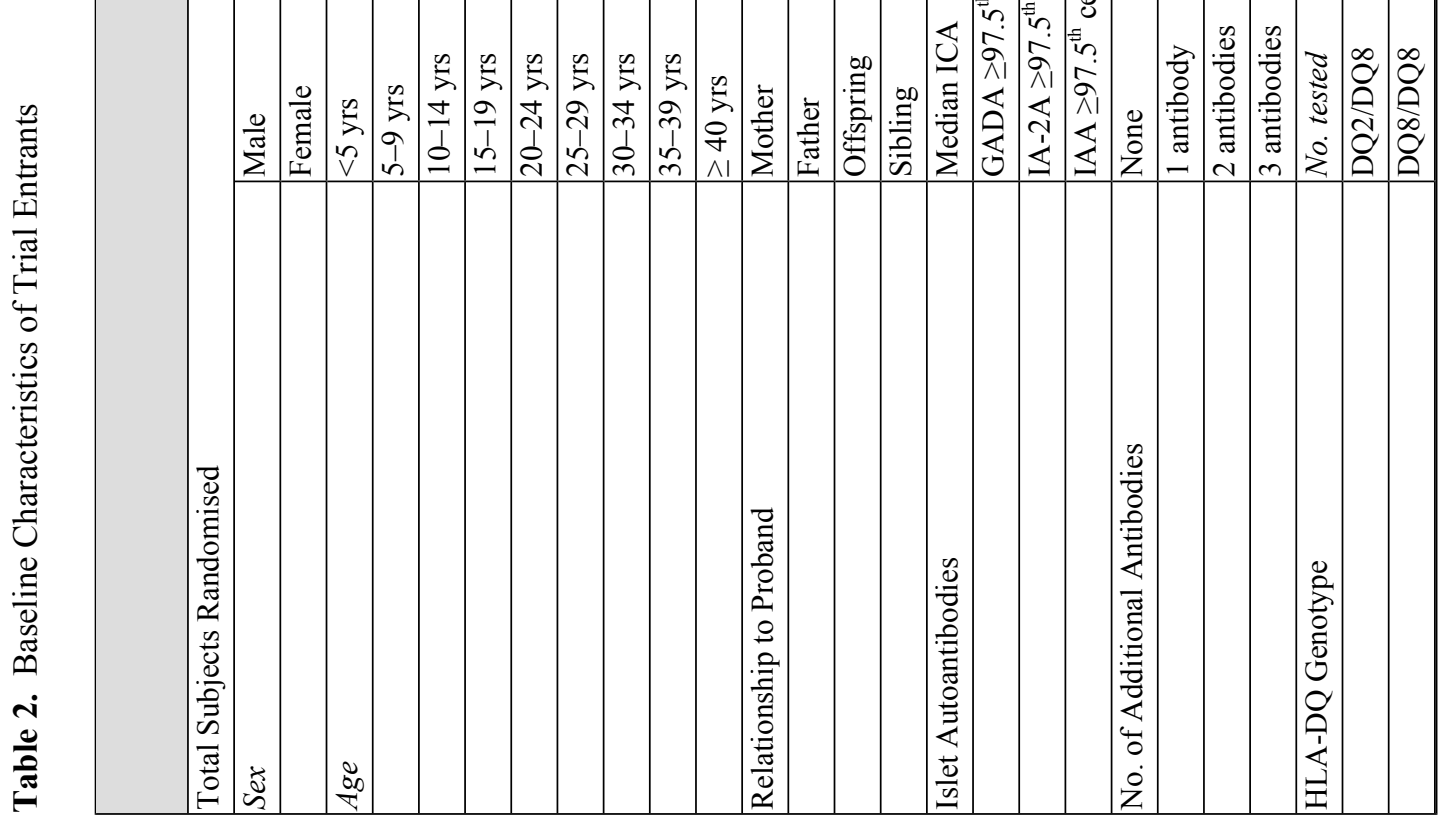




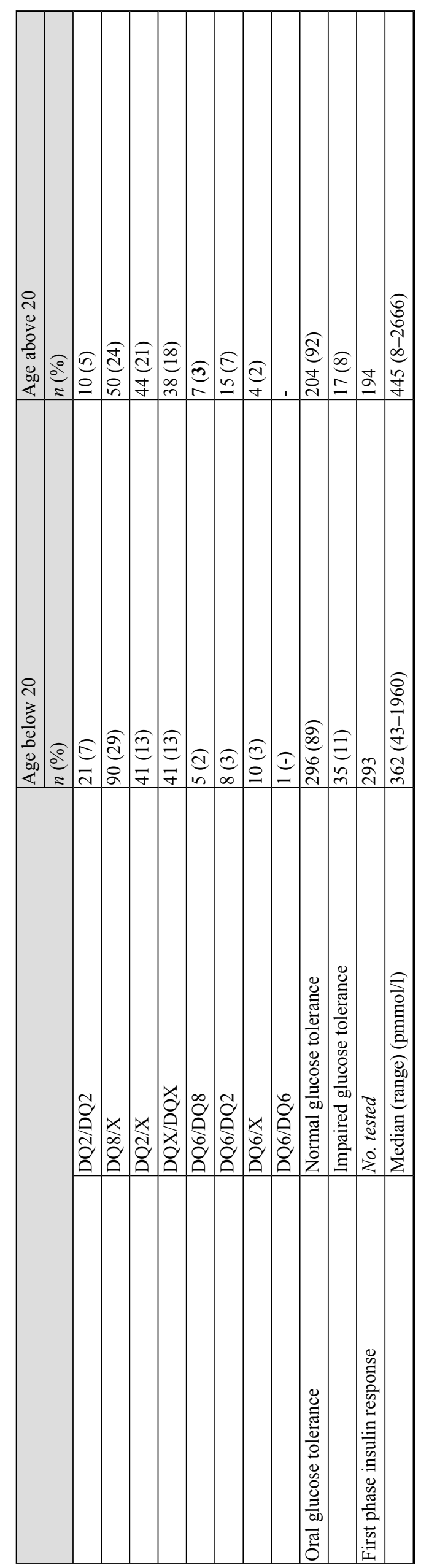

